九州大学学術情報リポジトリ

Kyushu University Institutional Repository

\title{
A chromatographic study of Brassica species having 10 pairs of chromosomes in somatic
}

Fukushima, Ei j i

Horticultural Laboratory, Department of Agriculture, Kyushu University

Iwasa, Shoichi

Horticultural Laboratory, Department of Agriculture, Kyushu University

https://doi.org/10.5109/22744

出版情報: 九州大学大学院農学研究院紀要. 13 (4)，pp.749-756，1966-02. Kyushu University バージョン：

権利関係 : 
Journal of the Faculty of Agriculture, Kyushu University, Vol. 13, No. 4, Fcbruary 15, 1966

\title{
A chromatographic study of Brassica species having 10 pairs of chromosomes in somatic*
}

\author{
Eiji Funushima and Shoichi Iwasa
}

Inquiries into the biochemical patterns of certain selected constituents of plants by means of the paper chromatography have become to be utilized as an useful tool of investigation on the taxonomic affinities with certain plant forms (Riley and Bryant 1961, Ellison et al. 1962), on the nature of certain hybrid populations (Alston and Turner 1962, McHale and Alston 1964, Tayler 1964), and as well as on the internal features of some polyploid taxa (Smith and Levin 1963, Stebbins et al. 1963, Torres and Levin 1964). Such chromatographic data have also been put to use in some field of horticulture as a reliable criterion for the easy identification in a certain group or among groups of species, subspecies or of varieties (Selle 1958, Teas et al. 1959, Singh and Thompson 1961, Rowlands and Janet 1963).

Genus Brassica and its related genera, to which a large number of vegetables, forages, and of oil crops belong, are one of those groups of plants that have been submitted to the detailed cytogenetical or morphological studies, but the detailed critical features of genetic differentiations occurred in those plants are not thoroughly disclosed yet. So that no less problems are still left to be solved in future studies through certain newly developed methods of approach. The present study on the several Brassica species having 10 pairs of chromosomes in somatic was undertaken to ascertain the applicability of the chromatographic technique and to obtain, in consequence, the phylogenetic informations with those species concerned. The cytogenetic data hitherto obtained were used in conjugation with the chromatographic data. Each form in Brassica with 10 pairs of chromosomes has usually been treated as an independent species, i. e., B. pekinensis, B. rapa, B.

* Contribution from the Horticultural Laboratory, Faculty of Agriculture, Kyushu University. 
chinensis, B. campestris, B. japonica, etc., but it is more preferable to assume that those species would be leveled down to the subspecific or the varietal rank of $B$. campestris or $B$. rapa according to the genetic informations presented in the following: The species composed of 10 pairs of chromosomes are capable of crossing freely with each other and the resultant $F_{1}$ hybrids are quite fertile, so that those species are considered to be composed of genome $a$ (cf. Sinskaia 1927, 1928, Morinaga 1928, 1934, Kitamura 1950, Olsson 1954). However, the $\mathrm{F}_{1}$ hybrids raised easily between $B$. trilocularis and any other forms showed certain anomalous meiotic divisions and resulted in the reduced fertililty, indicating presumably that $B$. trilocularis is possessing $\boldsymbol{a}^{\prime}$ genome, somewhat differentiated from $\boldsymbol{a}$ (Sikka 1940, Olsson 1954, Fukushima and Iwasa 1965). B. tournefortii, another species belonging to the group of 10 -chromosome species, showed definite

Table 1. Material species and varieties in Brassica having 10 pairs of chromosmes.

\begin{tabular}{|c|c|c|c|}
\hline Species & $\begin{array}{l}\text { Genome } \\
\text { constitution }\end{array}$ & $\begin{array}{l}\text { Horticultural } \\
\text { varieties }\end{array}$ & $\begin{array}{l}\text { Sources of } \\
\text { seed obtained }\end{array}$ \\
\hline $\begin{array}{l}\text { B. campestris } \\
\text { var. oleifera }\end{array}$ & $a a$ & Kanzaki-hanana & $\begin{array}{l}\text { A cultivated form in the } \\
\text { suburbs of Fukuoka city }\end{array}$ \\
\hline B. pekinensis (1) & $a a$ & Chifu-hakusai & Sakata Seed Co. \\
\hline B. pekinensis (2) & & Kashin-hakusai & " \\
\hline B. rapa (1) & $a z$ & Komatsu-na & " \\
\hline B. rapa & & $\begin{array}{l}\text { Honbeniakamaru- } \\
\text { kabu }\end{array}$ & " \\
\hline B. japonica & $a a$ & $\begin{array}{l}\text { Okute-shiraguki- } \\
\text { chisuzi-kyona }\end{array}$ & $" 1$ \\
\hline B. trilocularis & $a^{\prime} a^{\prime}$ & & $\begin{array}{l}\text { Plant-Breeding Laboratory, } \\
\text { Tohoku University }\end{array}$ \\
\hline B. tournefortii & $T T$ & & "I \\
\hline
\end{tabular}

Table 2. Cytogenetic data concerning $F_{1}$ hybrids raised among $\boldsymbol{B}$. campestris, B. pekinensis, B. trilocularis and B. tournefortii (compiled according to Fukushima and Iwasa 1965).

\begin{tabular}{|c|c|c|c|}
\hline & $\begin{array}{l}\text { B. campestris } \\
\times B \text {. pekinensis }\end{array}$ & $\begin{array}{l}\text { Combinations of } \mathrm{F}_{1} \text { hybrids } \\
\text { B. campestris B. campestris } \\
\times \text { B. trilocularis } \times \text { B. tourneforti }\end{array}$ & $\begin{array}{l}\text { B. tournefortii } \\
\text { tii } \times \text { B. trilocularis }\end{array}$ \\
\hline $\begin{array}{l}\text { Pollen- } \\
\text { fertility } 1)\end{array}$ & 95.8 & 76.5 & 0 \\
\hline $\begin{array}{l}\text { Seed- } \\
\quad \text { fertility } 2)\end{array}$ & 67.0 & 27.6 & 0 \\
\hline $\begin{array}{l}\text { Chromosome } \\
\text { pairings } \\
\text { at MI }\end{array}$ & $(9-10)$ & $(0-5)_{\mathrm{II}}+(20-10)_{\mathrm{I}}$ & $(0-4) I I+(20-12) I$ \\
\hline
\end{tabular}

N. B. 1) $\%$ of well-stained mature pollen-grains.

2) $\%$ of viable seeds with the ovules developed under the open-pollination. 
specificity in its morphology, and was highly cross-incompatible with any other form in this group. And moreover, the rarely obtained $F_{1}$ hybrids from such cross-combination were remarkably anomalous in their meiotic divisions and behaved utterly sterile, so that this form may be duly assigned to be possessing an entirely new genome $T$, a genome not encountered yet in any other Brasssica forms with 10 pairs of chromosomes (see Table 2).

\section{Materials and methods}

Those species with 10 pairs of chromosomes in somatic, as shown in Table 1 , are not sufficiently numerous to give a comprehensive information on such group of Brassica species, but they, including $\boldsymbol{B}$. trilocularis and $B$. tournefortii, are expected to enable one to get general features of genetic differentiations occurred in the formation of this group of forms.

Well-developed foliage leaves to be prepared into specimens were collected from several young plants grown up uniformly to the age of 60 days under a nursery greenhouse; the leaf-blades were first removed of their petioles, each $10 \mathrm{~g}$ of them was cut into pieces and added with $100 \mathrm{cc}$ of methanol; then this mixture was boiled for 1520 minutes and filtered after sufficient cooling; the filtrate was concentrated at about $50^{\circ} \mathrm{C}$ under reduced pressure and washed in petroleum ether. The extracts were spotted on Toyo filter-paper No. 50 and then developed into 2-dimensions by the ascending method. The solvents used were (1) iso-butanol, acetic acid and water (4:1:1 v/ v) for the first dimension, and (2) distilled water for the second. Each dried chromatogram was examined in daylight in the presence of ammonia vapour, in ultraviolet light, and in ultraviolet light in the presence of ammonia vapour. The chromatograms obtained with each of species or variety did not show any remarkable variation with the progress of growing of seedlings, as clearly revealed by the comparison of the mature leaves collected on the 30 th, 40 th and 60 th days of growing respectively.

\section{Results and consideration}

The spots detected throughout all the chromatograms could be distinguished by their Rf values and their fluorescent colourings, and some of them by the co-chromatography. Each spot was then given a numeral (Fig. 1). The chemical nature of the compounds represented by their spots could not be fully identified, because the comparison of "biochemical profiles" for the methanol-soluble leaf extracts with the species or varieties used was of purpose in the present study. Out 
of spots detected on the chromatogram, some were readily discernible for their quantitative prominence and their conspicuous positions, respectively, but some were hardly recognizable for their quantitative insignificance, and other so closely adjoined together as to be hardly distinguishable one from another. It will be expected, accordingly, that in case a much more detailed chromatogram by certain future techniques be obtained afresh, some additional informations thus obtained will become to revise in some way or other the present results by chromatographic data. And yet, it may be well admitted that the evidences reviewed in the present study would be duly accepted as a whole, because the revisions which are expected to be quite minor as compared to the general pattern.

From the analyses of chromatograms ca. 51 different compounds could be detected in the present group of Brassica species having 10 pairs of chromosomes. The numbers of total compounds and of specific ones (or unique ones, within the group studied; cf. Ellison et al. 1962) detected on the chromatograms with each species or variety are given in Table 3. It will be ascertained that B. tournefortii is remarkably

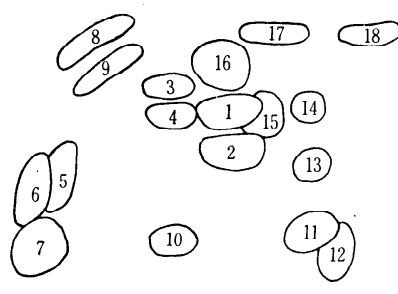

a

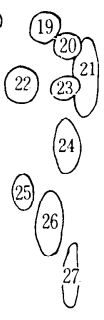

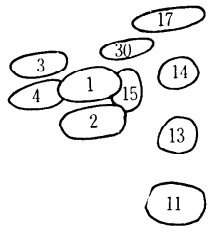

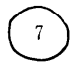

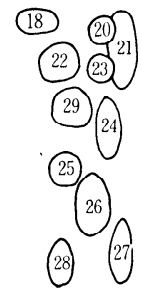

b
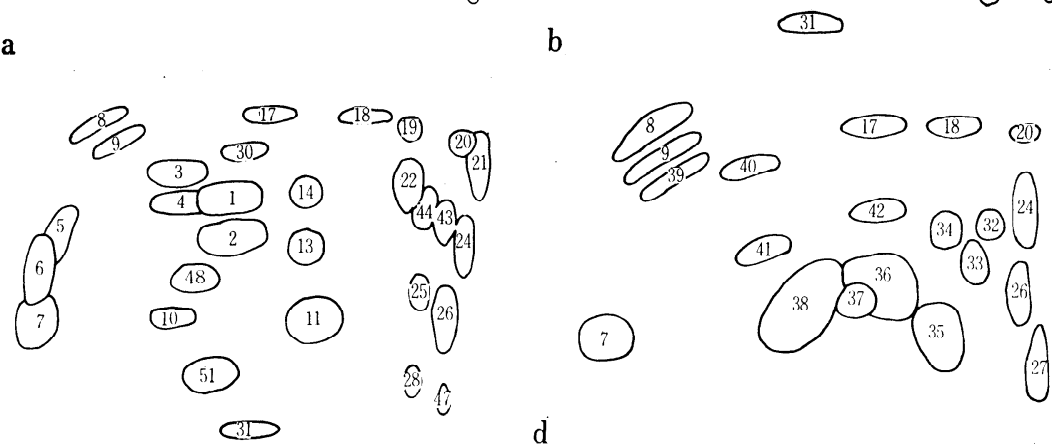

d

Fig. 1. Composite chromatographic patterns of methanol-soluble leaf extracts of the 4 species of Brassica: B. campestris var. oleifera (a); B. pekinensis Kashinhakusai (c); B. trilocularis (b); and $B$, tournefortii (d). 
Table 3. Number of chemical compounds which have been well detected upon the chromatogram.

\begin{tabular}{lcc}
\hline \multicolumn{1}{c}{ Species } & $\begin{array}{l}\text { Number of } \\
\text { specific compounds }\end{array}$ & $\begin{array}{c}\text { Total number } \\
\text { of compounds }\end{array}$ \\
\hline B. campestris var. oleifera & 1 & 27 \\
B. pekinensis $(1)$ & 1 & 30 \\
B. pekinensis $(2)$ & 1 & 31 \\
B. rapa $(1)$ & 0 & 27 \\
B. rapa (2) & 0 & 28 \\
B. japonica & 1 & 32 \\
B. trilocularis & 1 & 23 \\
B. tournefortii & 11 & 20 \\
\hline
\end{tabular}

different by its chromatographic pattern from the other species, 11 out of 20 detected compounds with this species being quite specific. Each species excepting B. tournefortii is found to have 23-32 compounds appearing on its chromatogram, of which $0-1$ seems to be specific. Throughout those species excepting $B$. tournefortii 14 compounds usually occurred in common, and they attained to the nearly half of the number of compounds detectable in their chromatograms, showing that those species are very similar in their chromatographic patterns. The spots, from No. 1 through No. 9, out of those spots having common occurrence in those species could be easily defined and distinguished, and B. trilocularis, which shows definite lack of the spots, Nos. 5, 6, 8 and 9 , in its chromatogram, became to be clearly discriminated from other forms, such as B. pekinensis, B. rapa, B. japonica and $B$. campestris var. oleifera (Fig. 1, C). Though they show a general resemblance in their chromatographic patterns, B. pekinensis, B. rapa, $B$. japonica and $B$. campestris var. oleifera could be discriminated with each other to some minor points, and $B$. campestris var. oleifera is more or less distantly situated from the former ones as shown by its spotpattern.

Ellison et al. (1962) succeeded in introducing a useful method of their device in expressing a quantitative relationship of chromatographic data obtained with the genus Bahia and its related genera. The present authors have tried to apply the concepts of the paired affinity (PA) and of the group affinity (GA) proposed by Ellison et al. to the results of present study. The paired affinity was obtained by the following formula:

$$
\mathrm{PA} \text { value }=\frac{\text { spots in common for species } A \text { and } B}{\text { total spots in } A+B} \times 100
$$

The group affinity (GA) value was equivalent to the sum total of the respective $\mathrm{PA}$ values of a given species for all the species compaired; 
for example, if 8 species were under study, the maximum GA value would be 800 , and the minimum would be 100 (that is, since the PA of species $A$ to species $A=100$, and the PA of species $A$ to any other species $=0$, then the minimum GA value $=100$ ). (cf. Alston and Turner 1963).

According to the PA values compiled in Table 4 the authors have classified the species used in 4 different groups: (1) B. tournefortii, the PA values of this species versus each of other species attained 20 or thereabout; (2) B. trilocularis and (3) B. campestris var. oleifera, the PA values of both the species versus all other species, excepting $B$. tournefortii, were 60 or thereabout (the PA value between two species, amounting to ca. 60 , will be available as a line of demarcation between them); (4) B. pekinensis, B. rapa, B. japonica, the PA values between any two of these species exceeded 70 (the true nature of affinity relationship among these species belonging to this (4) group will be obtained after much more related species have been fully examined from the same point of view). And further, the classification mentioned above will be denoted more concisely by the use of GA value of each species examined (Table 4).

The potential difference, however, existing probably on the affinity relationship between $B$. trilocularis and $B$. campestris var. oleifera against any of the species in the (4) group could not be referred to the PA or GA values. It seems, therefore, necessary for the purpose that the $\mathrm{PA}$ and $\mathrm{G}$ ! values must supplemented by the consideration on the

Table 4. Values of paired affinity and those group affinity, obtained with a number of 10-chromosome species in Brassica.

\begin{tabular}{|c|c|c|c|c|c|c|c|c|c|}
\hline & \multicolumn{8}{|c|}{ Paired affinity (PA) } & \multirow[b]{2}{*}{$\begin{array}{l}\text { Group } \\
\text { affinity } \\
\text { (GA) }\end{array}$} \\
\hline & 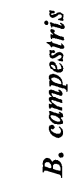 & 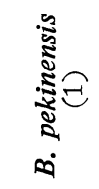 & 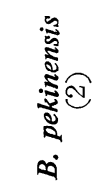 & $\frac{8}{8}$ & $\frac{\sqrt{2}}{2}$ & 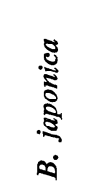 & 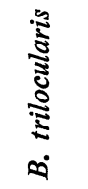 & 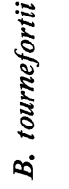 & \\
\hline B. campestris & 100 & & & & & & & & 490 \\
\hline B. pekinensis (1) & 62.9 & 100 & & & & & & & 548 \\
\hline B. pekinensis (2) & 56.8 & 79.4 & 100 & & & & & & 569 \\
\hline B. rapa (1) & 63.6 & 78.1 & 81.3 & 100 & & & & & 554 \\
\hline B. rapa (2) & 61.8 & 75.8 & 84.4 & 71.9 & 100 & & & & 551 \\
\hline B. japonica & 59.5 & 77.1 & 90.9 & 78.7 & 87.5 & 100 & & & 568 \\
\hline B. trilocularis & 61.3 & 55.9 & 54.3 & 61.3 & 50.0 & 52.8 & 100 & & 455 \\
\hline B. tournefortii & 23.7 & 19.0 & 21.4 & 20.5 & 20.0 & 20.9 & 19.4 & 100 & 245 \\
\hline
\end{tabular}


genome-specific spots, i. e., the spots, Nos. 1-9, detected in the $a$ genome species examined.

The present informations obtained by the more or less limited chromatographic data on the phylogenetic relationship existing among several Brassica species having 10 pairs of chromosomes did not only agree with, but also were duly supplementary to, those furnished by the cytogenetic data hitherto obtained with those species. It became quite apparent from the present study that chromatographic analyses are expected to furnish an effective mean by which the still advanced phylogenetic interrelationship among those species or varieties in Brassica and its related genera could be duly assessed.

\section{Summary}

A chromatographic study of several Brassica species having 10 pairs of chromosomes in somatic was undertaken to ascertain the availavility of such chromatograms of certain limited biochemical constituents for the analysis of phylogenetic relationships established among a member of species or varieties in Brassica.

The information thus obtained chromatographically showed a good agreement with the results obtained by cytogenetical studies. In addition, the chromatographic data had succeeded in defining clearly the profile of genetic differentiation occurring within the group of $a$ genome species. And further, the identification of species or varieties in Brassica was duly facilitated through the reference to biochemical patterns revealed by the methanol-soluble leaf extracts.

\section{Literature cited}

Alston, R. E. and B. L. Turner 1959. Applications of paper chromatography to systematics : Recombination of parental biochemical components in a Baptisia hybrid population. Nature 184: 285-286.

— and 1962. New techniques in analysis of complex natural hybridization. Proc. Nat. Acad. Sci. (U.S.A.) 48: 130-137.

— and - 1963. Biochemical systematics. Prentice-Hall, New Jersey, p. 338-339.

Ellison, W. L., R. E. Alston, and B. L. Turner 1962. Methods of presentation of crude biochemical data for systematic purposes, with particular reference to the genus Bahia (Compositae). Amer. Jour. Bot. 49: 599-604.

Fukushima, E. and S. Iwasa 1965. Genome-analytic studies on Brassica trilocularis and B. tournefortii. Jour. Fac. Agric. Kyushu Univ. 13: 743-748.

Kitamura, S. 1950. The cultivated Brassicae of China and Japan. Mem. College Sci. Univ. Kyoto, Ser. B, 16:1-6.

McHale, J. and R. E. Alston 1964. Utilization of chemical patterns in the analysis of hybridization between Baptisia leucantha and B. sphaerocarpa. Evolution 18: 304-311. 
Morinaga, T. 1928. Preliminary note on interspecific hybridization in Brassica. Proc. Imp. Acad. Japan 4: 620-622.

1934. Interspecific hybridization in Brassica VI. The cytology of $F_{1}$ hybrids of $B$. juncea and B. nigra. Cytologia $0: 62-67$.

Olsson, G. 1954. Crosses within the campestris group of the genus Brassica. Hereditas $40: 398-410$.

Riley, H. P. and T. R. Bryant 1961. The separation of some species of the Iridaceae by paper chromatography. Amer. Jour. Bot. 48: 133-137.

Rowlands, D. G. and J. J. Corner 1963. Biochemical differences as varietal characteristics for peas, beans and spinach. Hort. Res. 3: 1-12.

Selle, R. M. 1954. Determination of sour orange rootstocks by paper chromatography. Nature 174: 140-141.

- 1958. Spot chromatography identification of Citrus rootstocks. Nature 181: 506-507.

Sikka, S. M. 1940. Cytogenetics of Brassica hybrids and species. Jour. Genet. 40: 441-509.

Singh, K. and B. D, Thompson 1961. The possibility of identification of vegetable varieties by paper chromatography of flavonoid compounds. Proc. Amer. Soc. Hort. Sci. 77 : 520-527.

Sinskaia, E. N. 1927. Geno-systematical investigations of cultivated Brassica. Bull. Appl. Bot. Genet. P1. Breed. 17: 1-166.

- 1928. The oleiferous plants and root crops of the family Cruciferae. Ibid. $19: 1-648$.

Smith, D. M. and D. A. Levin 1963. A chromatographic study of reticulate evolution in the Appalachian Asplenitum complex. Amer. Jour. Bot. 50: 952-958.

Stebbins, G. L., B. L. Harvey, E. L. Cox, J. N. Rutger, G. Jelencovic, and E. Yagil 1963. Identification of the ancestry of an amphidiploid Viola with the aid of paper chromatography. Amer. Jour. Bot. 50: 830-839.

Taylor, A. O. 1964. A biochemical approach to some taxonomic problems in the genus Coprosma. New Phyt. 63: 135-139.

Teas, H. J., H. F. Winters and N. Almeyda 1959. Identification of mango varieties by paper chromatography. Proc. South Agr. Workers 56: 223.

Torres, A. M. and D. A. Levin 1964. A chromatographic study of cespitose zinnias. Amer. Jour. Bot. 51: 639-643. 